\title{
FAMILIAL SPASTIC PARESIS WITH STRABISMUS
}

BY

\author{
M. P. CROWE, F.R.C.P.I., D.P.D., T.D.D. \\ Deputy Medical Officer of Health, Dublin
}

This article describes a condition which, occurring among the five children of a family, seems of sufficient interest to merit publication. Two of these children were first seen at routine school medical inspection, and on learning that the remaining three children were somewhat similarly affected, a visit was made to their home and the following facts ascertained.
Their births were normal, no instruments being used: the present disabilities were noticed in early infancy, but since then have shown no tendency to spread. Otherwise there is nothing abnormal in their history. Clinically the five children show varying degrees of muscular weakness, confined to their lower limbs: the resulting incapacity permits three of the children, AX, aged 17 years; CX, aged 13 years; and DX, aged 11 years, to move

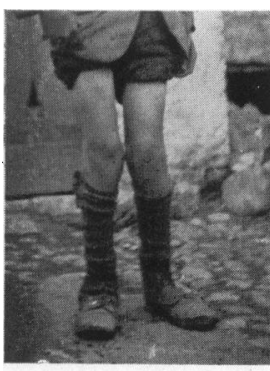

AX

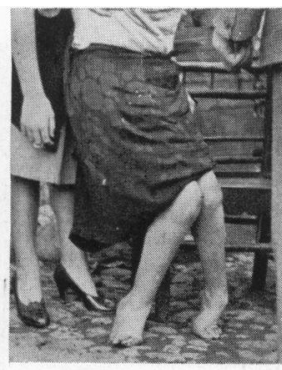

BX

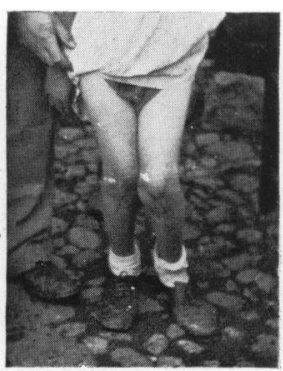

CX

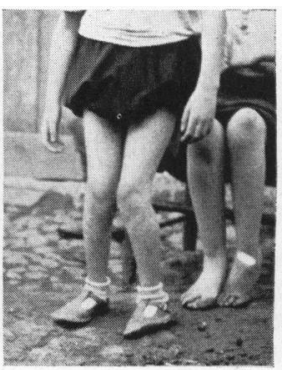

DX

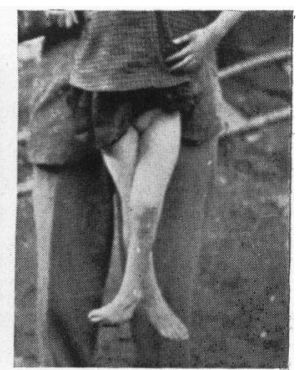

EX

FIG. 1.

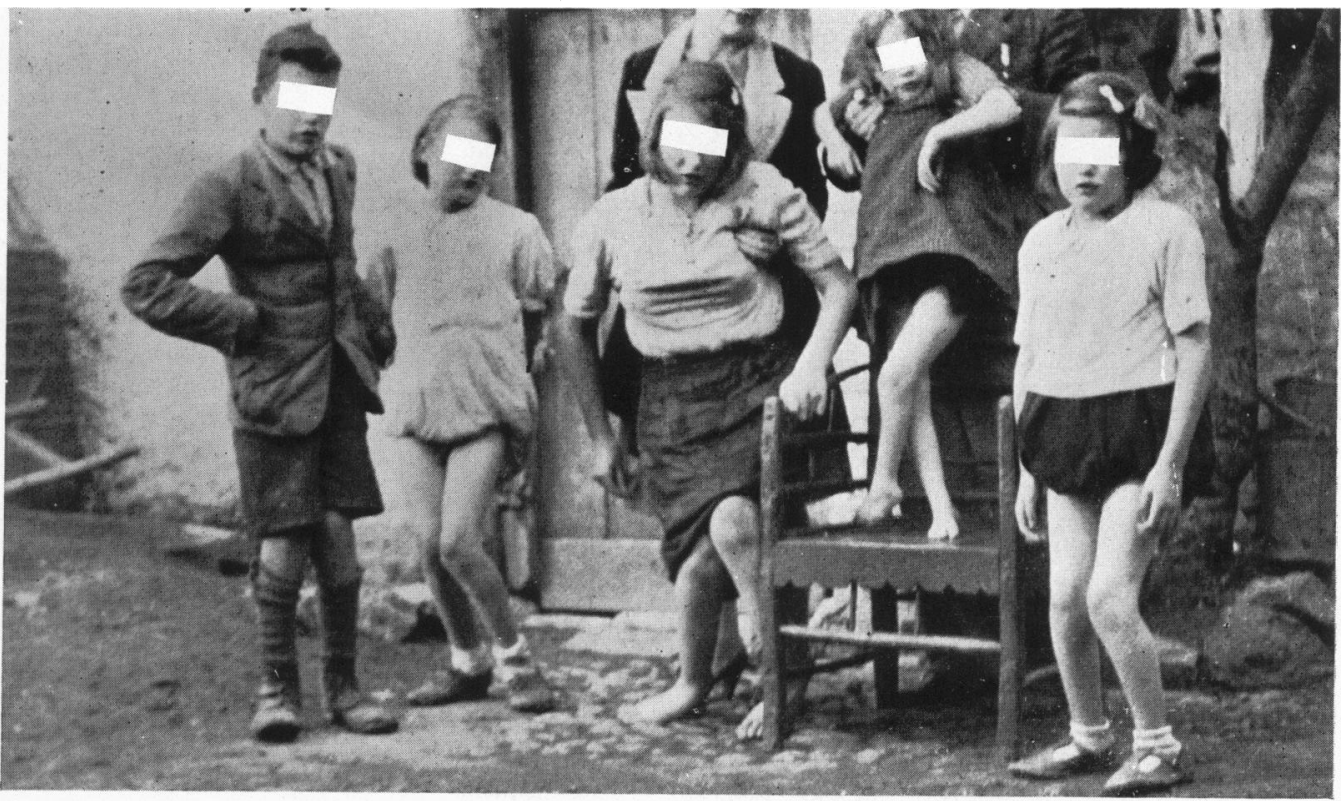

$\mathrm{AX}$

CX

BX

EX

DX

FIG. 2. 
about in a slow 'shuffling' manner; BX, aged 16 years, can only propel herself by holding on to a chair, whereas the youngest, EX, aged 7 years, cannot stand by herself and is the most seriously affected.

Muscle tone is decidedly spastic in the lower limbs of the five children: all have markedly increased knee and ankle jerks, together with increased ankle clonus, but only in AX could a definite plantar extensor response be obtained. All show varying degrees of 'scissors' gait, the posture being most marked in EX (fig. 1 and 2).

Club foot is marked in the case of BX and EX, while it had been also present in AX but was rectified by surgery.

Different degrees of hypermetropia, accompanied by loss of vision, exists in each child and strabismus is present in four, i.e. AX (left external strabismus), CX (right internal strabismus), and DX and EX (left internal strabismus). Visual acuity is about 6/12 in each case.

Sensation generally, and upper limbs, are normal.

Mentally they are about two years behind the average child of their age.

Their parents have always enjoyed good health and suffer from no defects. They are not related: no record of any deformity in either of their families can be elicited. Mr. X (father) at present does heavy manual work and Mrs. X (mother) is busily engaged looking after her five children: she had three miscarriages, one before birth of first child, one between second and third, and one following the last child.
The blood Wassermann reactions of parents and five children are negative.

\section{Discussion}

The presence of different degrees of loss of power, spasticity and adduction deformity of lower limbs in the five children of a family is described. Signs of an upper motor neurone lesion are present in all cases. This condition, first noticed in infancy and presumably present ante-natally, resembles the clinical entity described as Little's disease, with, in addition, the presence of ocular manifestations.

\section{Conclusion}

The occurrence of the five cases in the one family would seem to eliminate an infective or traumatic etiology and their origin probably is, as described by Collier (1924), 'a primary neuronic degeneration due to factors which are at present entirely elusive.' An obscure common deprivation process may exist, but if a genetic factor is responsible, seeing neither the parents nor grandparents have any similar defects, it would seem to be of the recessive rather than dominant type. As the parents are not related, this must be a marked coincidence.

\section{REFERENCE}

Collier, J. (1924) Proc. roy. Soc. Med., (Sect. Neurol.), $17,1$. 